\title{
Application of the AHP and TOPSIS in project management
}

\author{
Armin Jabbarzadeh ${ }^{\mathbf{a}^{*}}$
}

a Business School, McMaster University, Ontario, Canada

CH R O I C L E A B S T RAC T

Article history:

Received: July 5, 2017

Received in revised format: Octo-

ber 10,2017

Accepted: December 5, 2017

Available online:

January 2, 2018

Keywords:

Contractor selection

AHP

TOPSIS

\begin{abstract}
Selection of an appropriate contractor plays an important role for the success of the accomplishment of any construction project. This paper presents a multi-criteria decision making method for contractor selection. The proposed study uses six criteria, namely; Experience, Financial stability, Quality performance, Manpower resources, Equipment resources and Current workload for evaluating different contractors. Using analytical hierarchy process, the study ranks these criteria and finds the relative importance of them. Next, The technique for Order of Preference by Similarity to ideal Solution (TOPSIS) is used to rank the alternative contractors according to these criteria.
\end{abstract}

\section{Introduction}

Most project managers are encountered with decision environments and issues in projects which are complex in nature. There are various components involved with the contractor selection, and the interrelationships among the elements are relatively complicated. Relationships among various elements of a problem could be highly nonlinear and any change in the elements would not be necessarily associated with simple proportionality. Moreover, human value and judgement systems are essential elements of project problems. Thus, the ability to make appropriate decisions plays essential role for the success of a project (Al-Harbi, 2001).

Multiple criteria decision-making (MCDM) techniques are the main parts of decision theory and analysis. They look for more than one criterion in supporting the decision process. The primary objective of all MCDM techniques is to assist decision-makers to get some insight about the problems they encounter, to learn about organizational objectives, and through exploring these in the context of the problem to help them in detecting a preferred course of action (Al-Harbi, 2001).

* Corresponding author.

E-mail address: Jabbarza@memaster.ca (A. Jabbarzadeh) 
Contractor selection is one of the primary activities when a typical construction project is to be completed. Without a proper and precise method for choosing the most appropriate contractor, the performance of the project could be influenced, badly. MCDM is suggested to be a viable approach for contractor selection. The analytic hierarchy process (AHP) (Saaty, 1989) is a popular tool but it can only be employed in hierarchical decision models (Cheng \& Li, 2004). When a contractor is chosen, it is important to determine the relative importance of various criteria, which are normally vague in nature (Singh \& Tiong, 2005). Zavadskas et al. (2010) proposed a method for contractor selection for construction works by applying SAW-G and TOPSIS grey techniques (Hwang \& Yoon, 1981). Jaskowski et al. (2010) made an assessment on contractor selection criteria weights with fuzzy AHP method. Marzouk (2008) discussed the superiority and inferiority ranking model for contractor selection. Mahmoodzadeh et al. (2007) used both AHP and TOPSIS for ranking different projects based on four criteria; namely net present value, rate of return, benefit-cost analysis and payback period.

\section{The proposed study}

Selection of a construction contractor is generally involved with various factors. Some of the factors are related to financial figures and profitability while others are associated with job experience, equipment, etc.

\subsection{Factors influencing on selection of contractor}

Fig. 1 demonstrates the factors considered for the proposed study of this paper, which could impact on a construction project. As we can see from Fig. 1, there are six factors, which are important for the selection of a contractor. The first factor, Experience, is determined by different jobs accomplished by a firm in the past such as accomplishment of similar projects in the past. The second factor, Financial stability, is determined by looking at the firm's balance sheet and statement. The third factor, Quality performance, is determined on the quality of the previous works accomplished by the firm. Manpower resources is another important factor influencing on selection of a contractor, which is determined by the number of the full time employees as well as the access to other resources. Finally, Equipment and current workload are other important factors for choosing an appropriate contractor.

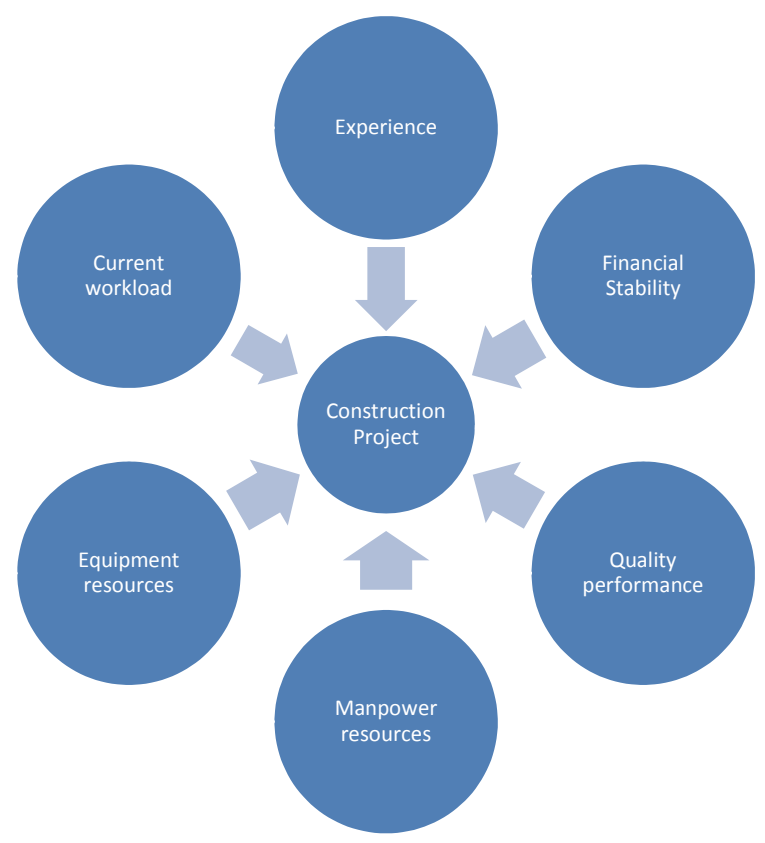

Fig. 1. The criteria influencing on choosing a construction project (Al-Harbi, 2001) 
Analytical hierarchy process (AHP) was first introduced by Saaty (1989) for ranking different criteria based on pairwise comparison. This method has been extensively used by many researches for ranking purposes. Al-Harbi (2001) for instance used the criteria mentioned in Fig. 1 to rank contractors.

\subsection{Technique for Order of Preference by Similarity to ideal Solution (TOPSIS)}

The technique for Order of Preference by Similarity to ideal Solution (TOPSIS) is considered as a multi criteria decision analysis method developed for the first time by Hwang and Yoon (1981). The method is based on the idea that the best alternative keeps the shortest geometric distance from the positive ideal solution (PIS) and maintains the longest geometric distance from the ideal negative solution (NIS). A PIS optimizes the benefit criteria / attributes. The following shows the necessary steps of TOPSIS:

\section{Step 1: Identifying evaluation attributes}

Identification of the aims and the assessment attributes for the study.

\section{Step 2: Evaluation matrix and obtaining normalized decision matrix}

Prepare an evaluation matrix, which has of $m$ attributes and $n$ criteria. The intersection of every attribute and criteria is given as $x_{i j}$. Normalize the decision matrix using the following equation:

$$
R_{i j}=\frac{x_{i j}}{\sqrt{\sum_{j=1}^{M} x_{i j}^{2}}},
$$

where $\quad i=1,2, \ldots . . m$ and $\quad j=1,2, \ldots . n$

Step 3: Obtain weighted normalized matrix

Make a decision on the relative importance (i.e. weights) of various attributes with respect to the objective in such a way that the sum weights of all attributes equals to 1 .

$$
\sum_{i=1}^{n} w_{i}=1
$$

Obtain the weighted normalized matrix by multiplying the normalized decision matrix by its associated weights. The weighted normalized decision matrix is formed as

$$
V_{i j}=w_{j} \times R_{i j}
$$

where $i=1,2, \ldots . . m, j=1,2, \ldots . n$ and $w_{j}$ is the weight of the $j^{t h}$ attribute.

Step 4: Determine positive ideal $(V+)$ and negative ideal $(V$-) solution

The positive ideal solution (PIS) and negative ideal solution (NIS) are chosen as follows:

$$
V^{+}=\left(V_{1}^{+}, V_{2}^{+}, \ldots, V_{n}^{+}\right) \text {maximum values and } V^{-}=\left(V_{1}^{-}, V_{2}^{-}, \ldots, V_{n}^{-}\right) \text {minimum values }
$$

Step 5: Calculate separation measures using n-dimensional Euclidean distance

Separate every alternative from the positive ideal solution (PIS) and negative ideal solution (NIS) as follows, 


$$
S_{j}^{+}=\sqrt{\sum_{i=1}^{n}\left(V_{i j}-V_{i}^{+}\right)^{2}} \text { and } S_{j}^{-}=\sqrt{\sum_{i=1}^{n}\left(V_{i j}-V_{i}^{-}\right)^{2}},
$$

where $j=1,2, \ldots, \mathrm{N}$.

\section{Step 6: Calculate closeness coefficient $(P)$}

Closeness coefficient $\left(\mathrm{P}_{\mathrm{j}}\right)$ for every strategy is calculated as follows:

$$
P_{j}=\frac{S_{j}^{-}}{S_{j}^{+}+S_{j}^{-}}
$$

Step 7: Determine percentage contribution of strategy:

The percentage contribution of every strategy is calculated as follows:

$$
P C_{j}=\frac{P_{j}}{\sum P_{j}} \times 100
$$

\section{Case study}

The case study of the proposed method consists of selection of five contractors, A, B, C, D and E. To evaluate these five firms, six criteria are defined as stated in Fig. 1 and the criteria are first ranked using AHP method. Table 1 shows the profile of the firms which are used from an example developed by AlHarbi (2001). Table 2 shows the results of pairwise comparison of six criteria.

\begin{tabular}{|c|c|c|c|c|c|}
\hline & Contractor A & Contractor B & Contractor $\mathrm{C}$ & Contractor D & Contractor E \\
\hline \multirow{3}{*}{ Experience } & 5 years experience & 7 years experience & 8 years experience & 10 years experience & 15 years experience \\
\hline & Two similar projects & One similar project & No similar project & Two similar projects & No similar project \\
\hline & & ecial procurement experience & 1 international project & & \\
\hline \multirow{3}{*}{ Financial stability } & $\$ 7 \mathrm{M}$ assets & $\$ 10 \mathrm{M}$ assets & $\$ 14 \mathrm{M}$ assets & $\$ 11 \mathrm{M}$ assets & $\$ 6 \mathrm{M}$ assets \\
\hline & High growth rate & $\$ 5.5 \mathrm{M}$ liabilities & \$6 M liabilities & \$4 M liabilities & $\$ 1.5 \mathrm{M}$ liabilities \\
\hline & No liability & Part of a group of companies & & Good relation with banks & \\
\hline \multirow{4}{*}{$\begin{array}{c}\text { Quality } \\
\text { performance }\end{array}$} & Good organization & Average organization & Good organization & Good organization & Bad organization \\
\hline & C.M. personnel & C.M. personnel & C.M. team & Good reputation & Unethical techniques \\
\hline & Good reputation & Two delayed projects & Government award & Many certificates & One project terminated \\
\hline & Many certificates & Safety program & Good reputation & Cost raised in some projects & Average quality \\
\hline \multirow{3}{*}{$\begin{array}{l}\text { Manpower } \\
\text { resources }\end{array}$} & Safety program & & $\mathrm{QA} / \mathrm{QC}$ program & & \\
\hline & 150 laborers & 100 laborers & 120 laborers & 90 laborers & 40 laborers \\
\hline & $\begin{array}{c}10 \text { special skilled } \\
\text { laborers }\end{array}$ & 200 by subcontract & Good skilled labors & 130 by subcontract & 260 by subcontract \\
\hline \multirow{8}{*}{$\begin{array}{l}\text { Equipment } \\
\text { resources }\end{array}$} & & Availability in peaks & 25 special skilled laborer & & \\
\hline & 4 mixer machines & 6 mixer machines & 1 batching plant & 4 mixer machines & 2 mixer machines \\
\hline & 1 excavator & 1 excavator & 2 concrete transferring trucks & 1 excavator & 10 others \\
\hline & 15 others & 1 bulldozer & 2 mixer machines & 9 others & 2000 sf steel formwork \\
\hline & & 20 others & 1 excavator & & 6000 sf wooden formwork \\
\hline & & 15,000 sf steel formwork & 1 bulldozer & & \\
\hline & & & 16 others & & \\
\hline & & & $17,000 \mathrm{sf}$ steel formwo & & \\
\hline \multirow{2}{*}{$\begin{array}{c}\text { Current } \\
\text { works load }\end{array}$} & $\begin{array}{l}1 \text { big project } \\
\text { ending }\end{array}$ & $\begin{array}{l}2 \text { projects ending } \\
(1 \mathrm{big}+1 \text { medium })\end{array}$ & $\begin{array}{c}1 \text { medium project } \\
\text { started }\end{array}$ & 2 big projects ending & $\begin{array}{c}2 \text { small projects } \\
\text { started }\end{array}$ \\
\hline & $\begin{array}{l}2 \text { projects in mid } \\
(1 \text { medium }+1 \text { small })\end{array}$ & & $\begin{array}{l}2 \text { projects ending } \\
(1 \text { big }+1 \text { medium })\end{array}$ & 1 medium project in mid & $\begin{array}{c}3 \text { projects ending } \\
(2 \text { small }+1 \text { medium })\end{array}$ \\
\hline
\end{tabular}

\section{Table 1}

Characteristics of five contractors 
Table 2

The results of pairwise comparison of different criteria and ranking them using AHP

\begin{tabular}{|c|c|c|c|c|c|c|}
\hline & Experience & Financial Stability & Quality performance & Manpower resources & Equipment resources & Current workload \\
\hline Experience & 1 & 2 & 3 & 6 & 4 & 5 \\
\hline Financial Stability & 0.5 & 1 & 0.3333 & 4 & 2 & 6 \\
\hline Quality performance & 0.3333 & 3 & 1 & 4 & 4 & 2 \\
\hline Manpower resources & 0.1667 & 0.25 & 0.25 & 1 & 0.25 & 2 \\
\hline Equipment resources & 0.25 & 0.5 & 0.25 & 4 & 1 & 2 \\
\hline Current workload & 0.2 & 0.1667 & 0.5 & 0.5 & 0.5 & 1 \\
\hline Rank & 0.3643 & 0.1867 & 0.2357 & 0.0558 & 0.1038 & 0.0539 \\
\hline
\end{tabular}

Based on the information provided in Table 1 one can assign a value from one to nine for each firm. Table 3 shows the results of the numbers. Here, higher numbers mean better position assigned for each firm.

Table 3

The data for the relative importance of different factors

\begin{tabular}{ccccccc}
\hline Contractor & Experience & $\begin{array}{c}\text { Financial } \\
\text { Stability }\end{array}$ & $\begin{array}{c}\text { Quality } \\
\text { performance }\end{array}$ & $\begin{array}{c}\text { Manpower } \\
\text { resources }\end{array}$ & $\begin{array}{c}\text { Equipment } \\
\text { resources }\end{array}$ & $\begin{array}{c}\text { Current } \\
\text { workload }\end{array}$ \\
\hline A & 4 & 8 & 8 & 8 & 5 & 8 \\
B & 6 & 8 & 4 & 6 & 7 & 7 \\
C & 6 & 9 & 7 & 8 & 9 & 5 \\
D & 7 & 9 & 5 & 7 & 3 & 6 \\
E & 9 & 7 & 2 & 8 & 7 & 9 \\
\hline
\end{tabular}

The implementation of TOPSIS method explained in section 2 based on the weights obtained for criteria using AHP and scores given to each firm in Table 3 yields the ranking of the firms shown in Fig. 2.

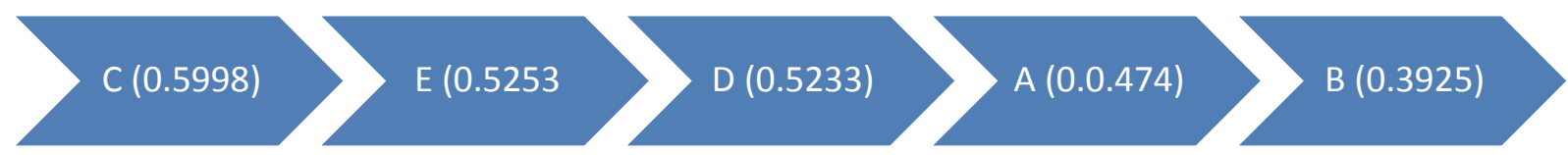

Fig. 2. The results of ranking five contractors using TOPSIS method

\section{Conclusion}

In this paper, we have proposed a method for contractor selection using a hybrid of analytical hierarchy process and TOPSIS. The proposed method has chosen six criteria and using AHP method ranked the relative importance of criteria. Using the weights obtained in AHP method, the proposed study has implemented TOPSIS and the results have been ranked, accordingly. The proposed study of this paper has not considered vagueness of the data based on different techniques such fuzzy or intervals numbers and we leave it for interested researchers as future study.

\section{Acknowledgement}

The authors would like to thank the anonymous referees for constructive comments on earlier version of this paper.

\section{References}

Al-Harbi, K. M. A. S. (2001). Application of the AHP in project management. International journal of project management, 19(1), 19-27. 
Cheng, E. W., \& Li, H. (2004). Contractor selection using the analytic network process. Construction management and Economics, 22(10), 1021-1032.

Hwang, C.L., \& Yoon, K.P. (1981). Multiple attribute decision making: methods and applications. New York: Springer-Verlag.

Jaskowski, P., Biruk, S., \& Bucon, R. (2010). Assessing contractor selection criteria weights with fuzzy AHP method application in group decision environment. Automation in construction, 19(2), 120126.

Mahmoodzadeh, S., Shahrabi, J., Pariazar, M., \& Zaeri, M.S. (2007). Project selection by using fuzzy AHP and TOPSIS technique. International Journal of Social, Management, Economics and Business Engineering, 1(6), 324-329.

Marzouk, M. (2008). A superiority and inferiority ranking model for contractor selection. Construction Innovation, 8(4), 250-268.

Saaty, T. L. (1989). Group decision making and the AHP. The analytic hierarchy process, 59-67.

Singh, D., \& Tiong, R. L. (2005). A fuzzy decision framework for contractor selection. Journal of Construction Engineering and Management, 131(1), 62-70.

Zavadskas, E. K., Vilutiene, T., Turskis, Z., \& Tamosaitiene, J. (2010). Contractor selection for construction works by applying SAW-G and TOPSIS grey techniques. Journal of Business Economics and Management, 11(1), 34-55.

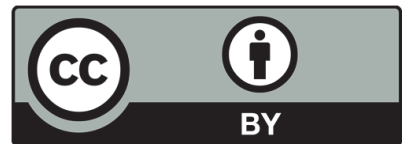

(C) 2018 by the authors; licensee Growing Science, Canada. This is an open access article distributed under the terms and conditions of the Creative Commons Attribution (CC-BY) license (http://creativecommons.org/licenses/by/4.0/). 